\title{
LA CRIMINALIZACIÓN BRASILEÑA DE MANO DE OBRA INMIGRANTE LATINOAMERICANA EN CASAS DE APUESTAS CLANDESTINAS
}

\author{
A CRIMINALIZAÇÃO BRASILEIRA DA MÃO-DE-OBRA IMIGRANTE \\ LATINO-AMERICANA EM CASAS DE JOGOS CLANDESTINAS
}

THE BRAZILIAN CRIMINALIZATION OF LATIN AMERICAN IMMIGRANT LABOR IN

ILLEGAL GAMBLING ESTABLISHMENTS

\author{
Lucas Fernandes da Costa \\ Víctor Gabriel de Oliveira Rodríguez ${ }^{2}$ \\ Universidade de São Paulo, Brasil
}

\begin{abstract}
RESUMEN
El objetivo de este trabajo es analizar la protección penal brasileña de la fuerza laboral inmigrante en las casas clandestinas de juegos, considerando los actuales flujos migratorios latinoamericanos. Con este fin, primero se aborda el tema de la migración en el contexto de América Latina, en el cual Brasil aparece como uno de los principales destinos, describiendo su principal motivación en términos socioeconómicos y el propósito relacionado. A continuación, se considera la trata de personas como antecedentes para cuestionar cuál es el tratamiento dado al inmigrante usado como fuerza laboral en el escenario de la explotación de la actividad económica del juego como un mercado ilícito, además de intentar investigar cuál es el nivel de tutela penal a la trata de personas en esos supuestos.
\end{abstract}

PALABRAS CLAVE: inmigración latinoamericana; casas de apuestas clandestinas; Brasil; custodia penal del inmigrante.

\begin{abstract}
The objective of this paper is to analyze the Brazilian penal protection of the immigrant workforce in clandestine gambling places, considering the Latin American migratory flows. To this end, we will first address the issue of migration in the context of Latin America, in which Brazil figures as one of the main destinations, outlining its main motivation in socio-economic terms and the related purpose. We will then talk about trafficking in persons as a background to question how the immigrant who is used as a labor force is treated in the

\footnotetext{
${ }^{1}$ Doutorando pelo Programa de Pós-graduação Integração da América Latina da Universidade de São Paulo (Prolam-USP). Advogado. Bacharel em Direito pela Faculdade de Direito de Ribeirão Preto da Universidade de São Paulo (FDRP-USP). Contato: lucas.fernandes.costa@usp.br.

${ }^{2}$ Professor Associado de Direito Penal da Faculdade de Direito de Ribeirão Preto da Universidade de São Paulo (FDRP-USP). Livre-docente pela Faculdade de Direito de Ribeirão Preto da Universidade de São Paulo (FDRP-USP). Membro do Programa Interunidades Integração Latino-americana (PROLAM) da USP. Contato: victorgabriel@usp.br.
} 
scenario of exploiting gambling economic activity as an illicit market, as well as criminal enforcement to avoid this kind of exploitation.

KEYWORDS: Latin American migration; Brazil; clandestine gambling houses; criminal protection of the immigrant; criminalization of the immigrant.

\section{RESUMO}

O objetivo deste trabalho é analisar a tutela penal brasileira da mão-de-obra imigrante em casas de jogos clandestinos, considerando os fluxos migratórios latino-americanos. Para isso, trataremos, de início, do tema da migração no contexto da América Latina, tendo o Brasil como um dos principais destinos, traçando a sua principal motivação em termos socioeconômicos e a finalidade correlacionada. Em seguida, falaremos sobre o tráfíco de pessoas como pano de fundo para questionarmos como é tratado o imigrante que é utilizado como mão-de-obra no cenário da exploração da atividade econômica dos jogos de azar, enquanto mercado ilícito, bem como a tutela penal oferecida a ele pelo país.

PALAVRAS-CHAVE: Imigração Latino-Americana; Casas de Jogos Clandestinas; Brasil; Tutela Penal do Imigrante.

\section{INTRODUCCIÓN}

En el contexto de la globalización, las crecientes migraciones internacionales han sido objeto de una importante cantidad de contribuciones científicas, tanto teóricas como empíricas, que observan, entre varios aspectos, su diversidad, sus significados y sus implicaciones. Una considerable fracción de este marco de contribuciones (por ejemplo, los estudios más recientes sobre el tema: BEINE, BOURGEON e BRICONGNE, 2019; AZOSE e RAFTERY, 2019; LAVENEX, 2019) abordan las impactantes transformaciones socioeconómicas, políticas, demográficas y culturales que han tenido lugar internacionalmente, en especial desde la década de los ochenta. En este escenario, las tendencias actuales de los flujos migratorios internacionales han exigido la revitalización de paradigmas para su mejor conocimiento y comprensión. Así, se hace esencial incorporar nuevas dimensiones teóricas y una revisión de la definición de lo que sería, en realidad, el fenómeno migratorio. En este sentido, el tema de la lucha y los compromisos internacionales para la vigencia de los llamados derechos humanos de los migrantes es de gran importancia, en vista del papel conflictivo de los estados y las políticas sociales con respecto a los procesos 
internos e internacionales de distribución demográfica. Los movimientos migratorios internacionales se presentan como contrapartida de la reestructuración territorial mundial, que, a su vez, está relacionada con la reestructuración de los ciclos económicos productivos a escala planetaria. (GEDDES, 2019).

En el contexto internacional, es necesario definir cuáles países tendrán acceso al desarrollo, es decir, intentar decir cuáles de ellos tendrán éxito en convertirse en un modelo de desarrollo económico y social capaz de hacerles dejar de la franja gris de 'países en desarrollo'. En este escenario, miramos hacia los países latinoamericanos que, durante décadas, aunque con excepciones, experimentaron un proceso de democratización caracterizado, sin embargo, por crisis financieras, déficit fiscal, deudas externas e internas, estancamiento de sus procesos productivos, entre otros factores que, a su vez, conllevan al aumento de la pobreza, la desigualdad y la exclusión socioeconómica. Por lo tanto, aunque a menudo oscile entre la obediencia a los paradigmas económicos neoliberales y los intentos de aumentar la redención de las desigualdades sociales acumuladas, América Latina desarrolla estrategias para comprender y lidiar con los flujos migratorios internos, y en algunos casos, suministrar mayor dinamismo y un avance relativo en las políticas sociales que involucran directamente a quienes se mueven en los territorios de la extensa región. Estos desplazamientos se deben a varios motivos, como el cambio de residencia, el escape de situaciones precarias anteriores, la circularidad, la doble residencia o las estancias temporales, que ocurren en grupos o individualmente, a menudo con acciones ilegales o clandestinas. (GEDDES, 2019).

En este texto, hacemos foco en el tema de las casas clandestinas de apuestas en Brasil y la protección penal de la fuerza laboral inmigrante latinoamericana. La pregunta principal es si los inmigrantes, según el sistema legal brasileño, son tratados como agresores o víctimas cuando se utilizan como mano de obra en el contexto de ese extracto de mercado ilícito. Para ello, inicialmente abordamos el desarrollo de estudios sobre la inmigración latinoamericana en Brasil desde la década de 1950 hasta la década de 2000, haciendo hincapié en la evolución de los métodos de recolección de datos y su fiabilidad. Enseguida pasamos a la comprensión de los motivos y propósitos que desencadenan los flujos migratorios hacia Brasil, destacando los factores de expulsión en el contexto de la pobreza estructural, los factores de atracción socialmente construidos y las consecuencias de la migración interna. Finalmente, 
examinaremos el tema de la criminalización de la explotación comercial de los juegos de azar en el país y la protección penal de la fuerza laboral inmigrante.

\section{AMÉRICA LATINA Y LA MIGRACIÓN}

El fenómeno de la migración ha sido una constante en la realidad de América Latina y el Caribe. Aunque durante varios siglos América Latina fue un destino importante para muchas poblaciones europeas, africanas e incluso asiáticas. A principios del siglo XX, las migraciones sur-norte del período 1960-2010 profundizaron el carácter emisor de su estatus de receptor a nivel mundial (HERRERA, 2012). Por otro lado, en los últimos tiempos ha aumentado la migración económica y forzada en la subregión. Según la Comisión Económica para América Latina y el Caribe (CEPAL) (MARTÍNEZ PIZARRO ET AL., 2014), hubo un aumento en los flujos intrarregionales y transcontinentales entre 2000 y 2010, con los principales volúmenes de migrantes que iban de Colombia a Venezuela y Ecuador; de Centroamérica a México; de Haití a la República Dominicana; y de Nicaragua a Costa Rica. (HERRERA; SORENSEN, 2017).

Aunque los patrones migratorios hayan evolucionado constantemente en América Latina, la investigación sobre el tema no se ha desarrollado necesariamente en la misma medida y se encuentra lejos de ser exhaustiva. Sin embargo, es importante reconocer que la multiplicación de los perfiles de migración, así como una mirada más cercana a la diversidad de género y étnica, ha producido un creciente cuerpo de estudios. Esto nos permite hablar sobre el resurgimiento de los estudios migratorios en América Latina, un campo que ha permanecido relativamente letárgico desde la década de 1980, en el que se ha realizado un trabajo importante sobre la migración interna, vinculado a los procesos de urbanización y reestructuración agraria. En los últimos 20 años, hubo numerosas publicaciones sobre las causas y consecuencias de estas nuevas migraciones, su impacto en las sociedades de origen y destino, su feminización, su racialización y su diversificación socioeconómica. También tuvieron influencia en estos procesos migratorios las crisis sociales, políticas y económicas 
experimentadas en la región y con la creciente globalización de los mercados laborales. Finalmente, el interés en examinar el papel de los estados y las políticas de migración en estos procesos ha aumentado, particularmente en relación con la creciente aplicación de políticas de migración y control de fronteras. (HERRERA; SORENSEN, 2017).

América Latina ha experimentado un crecimiento considerable en sus migraciones en los últimos años. Este crecimiento ocurrió como parte de la intensificación de los procesos de globalización y también encuentra explicaciones en la intensificación de las crisis económicas y políticas que la región experimentó en diferentes territorios. Los cambios en los procesos de acumulación capitalista y la titulización de las fronteras son dos fenómenos que también han afectado en gran medida los movimientos de las personas en la región, reduciendo los flujos en algunos casos, redirigiéndolos a otros destinos en otros, aumentando los retornos voluntarios $\mathrm{y}$ forzados $\mathrm{y}$ también multiplicándose tipo de movilidad. (HERRERA; SORENSEN, 2017).

DONATO ET AL. (2010) identificaron tres patrones críticos de movimiento regional en los últimos 50 años: (1) migración sur-norte de América Latina a los Estados Unidos y Canadá, (2) migración interregional en América Latina y (3) migración transoceánica a Europa y Japón: ahora, si se estudian las migraciones Sur-Norte, se observan varios patrones. Primero, aunque la salida de personas a los Estados Unidos parece haber disminuido en los últimos 10 años de países como México (MASSEY, 2015) no se detuvo desde Ecuador, Bolivia y Colombia y aumentó desde América Central. En segundo lugar, en lo que respecta al Sur de Europa, las migraciones han disminuido significativamente en los últimos 10 años después de la crisis económica de 2008. Más allá de eso, existe una complejidad de estos flujos, además de las salidas de personas a los países del norte. Existieron procesos de retorno voluntario y forzado debido al aumento de deportaciones o reubicaciones a terceros países y una mayor visibilidad de los procesos de migración circular entre el Sur y el Norte.

De manera similar, junto con la migración sur-norte, más y más migrantes de otras regiones de América Latina y el sur global han llegado a las ciudades de nuestra región, incluso a aquellas que no tienen tradición internacional de migración, como las ciudades andinas. A tasas mucho más lentas que los flujos de dinero, material e información que circulan a nivel mundial, los migrantes intrarregionales y transcontinentales están cambiando la faz de las ciudades latinoamericanas, al igual que los migrantes internos en las décadas de 
1950 a 1970 en todo el subcontinente. Si bien estos flujos también son cultural y socioeconómicamente heterogéneos, la mayoría de estos nuevos inmigrantes contribuyen a las economías locales, a menudo basadas en trabajos precarios. En ciudades con poca tradición internacional de migración, este tipo de inserción predomina sobre los procesos de asentamiento definitivos y la integración social exitosa. Factores estructurales, relacionados con las economías de la ciudad, y factores políticos, que se refieren a la falta de visibilidad de la población inmigrante en las políticas locales, contribuyen a esta difícil inserción. (HERRERA; SORENSEN, 2017).

Merece la pena señalar que las causas de la migración no fueron estáticas o permanentes. Las necesidades económicas que se han acuñado para explicar por qué las personas abandonan sus comunidades para vivir en otros países, el desplazamiento forzado causado por la violencia, los megaproyectos de desarrollo o los desastres naturales se han sumado en ese contexto. En algunos territorios, la conjunción de todos estos fenómenos explica el aumento de la migración. Actualmente, en varias regiones de Colombia, México, Honduras, Guatemala, El Salvador, entre otros, los desplazamientos forzados de la población están en la agenda debido a la violencia social y política imperante en estos territorios. La movilidad causada por la violencia ha aumentado considerablemente en los últimos 20 años, desde los migrantes que buscan asilo en diferentes ciudades latinoamericanas como Quito, Santiago o San José hasta los migrantes clandestinos y vulnerables, como los niños y adolescentes no acompañados que viajan por México a la frontera Norte. (HERRERA; SORENSEN, 2017).

\section{LAS RAZONES, PROPÓSITOS Y CONSECUENCIAS DE LA INMIGRACIÓN LATINOAMERICANA A BRASIL}

SASSEN (2018) entiende que la migración, a pesar de en su raíz ser un acto de voluntad individual - todos los que migran llevan en sus mentes aspiraciones y razones personales - solo es posible ya que la opción de migrar es un fenómeno estructural desde la perspectiva de una estructura. (MARINUCCI; MILESI, 2005). La intensificación 
contemporánea de los múltiples flujos internacionales de bienes, personas y capitales eventualmente creó un único sistema planetario multipolar (GONÇALVES, 2009) caracterizado por la dualidad centro-periferia, mediada por una semi-periferia, un concepto que circunscribe espacios en los que el modo de producción capitalista se desarrolla en la dependencia financiera y técnica de las naciones del centro (GONÇALVES, 2009). Por lo tanto, la migración internacional sería el resultado de la división internacional del trabajo, que llevaría de los países periféricos a los países desarrollados la mano de obra barata que estos necesitan para el funcionamiento de sus economías (BAENINGER; MESQUITA, 2016). De hecho, para HARVEY (2012), una característica central de la globalización es la aparición de un ejército de reserva integrado, que elude la segmentación geográfica de los mercados laborales. Tal mirada a la migración internacional indica que la fuerza de atracción por el trabajo que ejercita los mercados laborales supera cualquier restricción que los estados puedan imponer a los flujos migratorios (BAENINGER; MESQUITA, 2016).

En este escenario, las migraciones internacionales han ganado importancia debido a las enormes transformaciones económicas, sociales, políticas, culturales e ideológicas experimentadas en el siglo XXI. Desde las décadas de 1980 y 1990, Brasil ya se insertó en este nuevo contexto de migraciones internacionales: bien con salidas de brasileños al extranjero, bien con la reciente llegada de inmigrantes al país. El tema de las migraciones internacionales está emergiendo como un tema demográfico en Brasil a fines del siglo XX. (BAENINGER; MEZQUITA, 2016). La historia de la formación social de la población brasileña se puede resumir en una serie de movimientos de inmigrantes en diferentes momentos de la economía (BAENINGER, 2012). Sin embargo, sólo a partir de la segunda mitad de la década de 1980 el tema de la migración internacional volvió a la agenda de investigación y la política del País. Inicialmente, fue el movimiento externo de los brasileños lo que llamó la atención, ya que más de un millón de ellos estaban fuera de Brasil en la década de 1990, principalmente en los Estados Unidos, Paraguay y Japón, y otros países. como Italia, Portugal, Inglaterra, Francia, Canadá, Australia, Suiza, Alemania, Bélgica, los Países Bajos e Israel. Sin embargo, es digno de mención que la emigración de brasileños a Paraguay data de la década de 1970, reapareciendo y siendo vista solo ahora en el nuevo contexto de migraciones transfronterizas (BAENINGER; MESQUITA, 2016). 
Desde distinta perspectiva, el fenómeno migratorio internacional en Brasil se observa por la entrada de nuevos contingentes de inmigrantes. El escenario de la globalización, además de acortar las distancias, ha redefinido las ubicaciones y creado bloques económicos, de modo que el país está asistiendo a la entrada de inmigrantes latinoamericanos, coreanos, asiáticos, haitianos y estadounidenses, franceses, coreanos, españoles y portugueses, con intensificación del movimiento de capitales y bienes. En el contexto de América Latina, hasta la década de 1970, Brasil figuraba como un área de evasión de población para los países vecinos, especialmente Paraguay y Argentina Argentina. El siglo XXI altera esta lógica, ya que el país se convierte en una de las áreas más fuertes de recepción de la migración para los latinoamericanos, pasando del cuarto mayor stock de estos extranjeros (alrededor de 190 mil), frente a unos 180 mil. Brasileños que viven en los países de la región. (BAENINGER; MEZQUITA, 2016).

Sin embargo, es necesario enfatizar la diversidad de flujos de inmigrantes y emigrantes internacionales. Por un lado, Brasil recibe flujos de mano de obra calificada de Chile, Argentina, Estados Unidos, Francia, Alemania, China, Corea, España y Portugal; Por otro lado, los inmigrantes van a estos países que, aunque tienen niveles de educación secundaria alta y superior, son trabajadores insertados en los niveles más bajos del mercado laboral. La diversidad de flujos en Brasil según la nacionalidad y el país de origen también necesita atención especial, como en el caso de bolivianos, paraguayos, peruanos, colombianos que se encuentran en una situación que revela la ausencia de derechos humanos para estos contingentes de población. En este sentido, destacamos el caso de la ciudad de São Paulo, entendida como el centro operativo de una región de capitalismo semiperiférico, ya que es el lugar de mayor concentración de inversión extranjera (SASSEN, 2018) en América Latina. Esta vez, se explica la atracción que la metrópoli ejerce sobre mano de obra calificada, cuya situación migratoria se ha regularizado desde su partida por parte de empleadores multinacionales y, al mismo tiempo, también sobre un contingente proveniente de la periferia del sistema mundial (BASSO, 2010).

En comparación, bolivianos, peruanos, colombianos, haitianos, senegaleses, congoleños, entre otros pueblos, están en gran medida vinculados a economías informales e invisibles a los ojos de la sociedad civil y el estado (VILLEN, 2012), revelando nuevos contornos de la migración internacional, algo que puede desvelar aspectos criminológicos 
relevantes, como en el caso de la trata de personas y la reducción de trabajadores a la condición análoga a la esclavitud. (BAENINGER; MEZQUITA, 2016).

\section{LA SITUACIÓN DEL TRABAJADOR INMIGRANTE LATINOAMERICANO EN EL CONTEXTO DE LA TRATA DE PERSONAS}

Tanto los factores individuales como las circunstancias externas contribuyen a la trata de personas en y desde América Latina y el Caribe. Los factores de riesgo individuales incluyen pobreza, paro, analfabetismo, antecedentes de abuso físico o sexual, falta de vivienda, uso de drogas y membresía a pandillas criminales. La OIM en Colombia ha identificado algunas características personales comunes entre las víctimas de la trata. Esto incluye una tendencia a correr riesgos para cumplir objetivos, un enfoque en recompensas a corto plazo que pueden resultar de inmediatos riesgos a la seguridad a la falta de apoyo familiar o redes sociales fuertes. Estos factores de peligro que pueden influir en una persona que acepta una oferta de trabajo arriesgada en otro país están contrastados a fuertes a factores de atracción, incluida la esperanza de encontrar oportunidades económicas en el extranjero, que se ven impulsadas por las imágenes ricas de televisión e Internet, por ejemplo, en Estados Unidos, Europa o incluso Brasil. (SEELKE, 2010).

Los factores que contribuyen a la trata de seres humanos son: (1) la alta demanda mundial de trabajadores domésticos, trabajadores agrícolas, trabajadores sexuales y mano de obra barata; (2) crisis políticas, sociales o económicas, así como desastres naturales que ocurren en ciertos países, como los recientes terremotos en Haití; (3) machismo persistente que tiende a conducir a la discriminación contra las mujeres y las niñas; (4) existencia de redes de tráfico establecidas con métodos sofisticados de reclutamiento; (5) corrupción pública, especialmente complicidad entre la policía y los agentes fronterizos con traficantes y contrabandistas extranjeros; (6) políticas restrictivas de inmigración en algunos países de destino que tienen oportunidades limitadas para que ocurran flujos de migración legal; (7) desinterés del gobierno hacia el control a la trata de personas; y (8) oportunidades económicas limitadas para las mujeres en América Latina. Aunque las mujeres han alcanzado los mismos 
(o mayores) niveles de educación que los hombres en muchos países, el empleo de las mujeres sigue concentrado en trabajos informales y de bajos salarios. (SEELKE, 2010).

Entre 1995 y 2008, el gobierno brasileño rescató a más de 30,000 trabajadores de situaciones laborales irregulares, en condiciones análogas a la esclavitud (COSTA, 2009). En Brasil, el trabajo forzoso es más común en áreas rurales aisladas, pero también ocurre en áreas urbanas, como fábricas clandestinas de ropas, casas de prostitución $\mathrm{y}$, como se verá en el siguiente tema, casas de juego clandestinas. Cabe señalar que uno de los principales destinos para los inmigrantes que vienen a Brasil en busca de mejores condiciones de vida, en términos de trabajo, son establecimientos clandestinos que explotan actividades económicas, a veces criminalizadas, a veces de manera irregular, en este último caso, tenemos ejemplos de pequeñas prendas tercerizadas que utilizan mano de obra esclava de inmigrantes, en su mayoría latinoamericanos, como es el caso de los bolivianos en la ciudad de São Paulo. (KEMPFER; MARTINS, 2013). Con respecto a las actividades criminalizadas, tenemos el ejemplo de las casas de prostitución y el tráfico de drogas. Sin embargo, con respecto a este texto, dirigimos la mirada específicamente a las casas de juegos clandestinas y la protección victimológica propuesta al trabajador inmigrante.

\section{LA CRIMINALIZACIÓN DE LAS CASAS DE APUESTAS EN BRASIL Y LA CRIMINALIZACIÓN DE LA MANO DE OBRA INMIGRANTE}

La declaración normativa del artículo 50 de la Ley de faltas penales (BRASIL, 1941) establece la descripción abstracta del tipo de delito que penaliza la explotación comercial de las apuestas. Al principio, tenemos las palabras "establecer o explotar". El primero se centra en el acto de crear, instituir, reafirmar, hacer cumplir, hacer que una práctica particular sea regular, estable, mientras que el tercero se centra en el acto de aprovechar, sacar provecho. La conjunción "o" entre ellos propone una suma entre estos comportamientos, agregando todos estos actos dirigidos, luego, a las apuestas, el siguiente término. En este sentido, en aras del elemento objetivo, tenemos comportamientos comisionados, asociados con el elemento 
subjetivo de la intención, es decir, dirigidos a un propósito específico, que no indican factores que enmarcan una conducta culpable, como imprudencia, negligencia o mala práctica.

En cuanto al término juego, el $\S 50$ del Artículo 50 establece definirlo en tres hipótesis: (1) el juego en el que la ganancia o pérdida depende exclusiva o principalmente de la suerte; (2) apuestas de carreras de caballos fuera de los lugares específicos previamente autorizados; (3) apuestas en cualquier otra competición deportiva. Sobre el concepto de juego de las hipótesis anteriores, ya hemos desglosado en líneas anteriores. Vale la pena señalar aquí que, observando el principio de legalidad propuesto para el área penal (BRASIL, 1988), no es factible una interpretación extensa del concepto más allá de estas tres situaciones: la norma penal debe interpretarse estrictamente y no permite analogías. (RODRÍGUEZ, 2010, p. 69-ss).

El juego no puede establecerse u operarse en un lugar público o accesible al público. En este sentido, se entiende como un lugar público, que está bajo el dominio del Gobierno, con interferencia del Estado, mientras que un lugar accesible al público, que, incluso bajo el dominio de lo privado, está abierto a la libre circulación de personas o incluso a grupos segmentados de la sociedad (clubes, por ejemplo). El párrafo 4 del artículo 50 equivale a un lugar accesible al público: (a) la casa privada en la que se realiza el juego con apuestas, cuando las personas que no son de la familia en cuya posesión generalmente participa; b) el hotel o la vivienda colectiva, cuyos huéspedes y residentes actúan en juegos de azar; c) el domicilio social o la dependencia de una empresa o asociación en la que se realiza el juego; y (d) el establecimiento destinado a la operación de juegos de azar, incluso si dicho destino está oculto. Con respecto a estas hipótesis, algunas consideraciones son válidas.

En relación a la casa privada en la que se realizan los juegos de azar, cuando los miembros que no son de la familia generalmente participan en ellos, tenemos una hipótesis excluyente, que debe leerse diametralmente opuesta, a saber: cuando los participantes de una familia que ocupa una casa practican juegos de azar dentro de ella, dentro del espectro de su privacidad, no se tipifica el comportamiento criminal. En este sentido, si los miembros de un hogar usan el juego, ya sea por diversión o para ganancia o pérdida, dicho establecimiento o explotación no está dentro de la esfera de posible intervención del Estado.

Con respecto a la hipótesis de un hotel o vivienda colectiva, cuyos huéspedes y residentes reciben juegos de azar, tenemos que considerar, incluso para fines de entretenimiento, los hoteles y casas de huéspedes no pueden ofrecer juegos de azar a sus 
huéspedes, ya que hay una operación hotelera comercial, que no puede asociarse con la práctica del juego, la cual, en esta hipótesis, podría confundirse con el propósito económico de la actividad, o incluso agregarse a su propósito principal. La misma lógica se aplica a la sede o dependencia de una sociedad o asociación en la que las apuestas se llevan a cabo, a riesgo, la sociedad o asociación, de constituirse para un propósito criminal y, en consecuencia, sus miembros acusados de organización criminal.

Finalmente, en lo que respecta al establecimiento de juego, a pesar de que este destino está disfrazado, tenemos un establecimiento que aparentemente está destinado a una actividad económica legal, como un mercado, una ferretería, un papelería o incluso un bar, pero en realidad obtiene su beneficio de la explotación comercial de las apuestas. Vale la pena señalar que, incluso si tenemos un establecimiento que es realmente para un propósito rentable a través de una actividad económica legal que promueve, ocasional o habitualmente, el juego, tenemos la tipificación de la falta delictiva, como bares o incluso tiendas, conveniencia que ofrecía a sus clientes la posibilidad de apostar en máquinas tragaperras, totalmente prohibidas por la ley brasileña.

Tras el análisis del artículo 50, al final de su caput, la criminalización del establecimiento o la explotación de los juegos de azar en un lugar público o accesible al público se configura con un pago inicial o sin él. En otras palabras, no es necesario que la explotación comercial ocurra con fines de lucro, siendo criminalizada incluso cuando el propósito es meramente lúdico, gratuito, no costoso. También vale la pena mencionar la disposición del párrafo 2 del artículo 50 de la Ley de Faltas Penales (BRASIL, 2015), que trata sobre el particular jugador, que incurre en una multa de dos mil a doscientos mil reales, si se encuentra que participa en el juego, incluso a través de Internet o cualquier otro medio de comunicación, como puntero o apostador. La declaración normativa se dirige correctamente al jugador que participa en el juego, incluida su presencia física u otros medios de comunicación, como Internet.

Y, finalizando el análisis del artículo 50 de la Ley de faltas penales, tenemos la causa del aumento de la pena de un tercio propuesto por su $\S 1$, que cuida de las hipótesis en que, en el establecimiento o la explotación del juego, haya empleados contratados para la actividad o participantes menores de dieciocho años. En la primera situación, observando el vínculo de subordinación y la situación de vulnerabilidad propuesta al empleado, en teoría, esto no puede 
enmarcarse en la tipificación del delito menor, aunque, si se observa su autonomía y ciencia con respecto al destino de la actividad, puede ser considerado como un agente en la práctica criminal. En el segundo, a su vez, los menores de dieciocho años son penalmente imputables, pero el Estatuto del Niño y el Adolescente establece que, al cometer delitos, delitos engendrados por menores, la autoridad competente puede aplicar medidas socioeducativas, que que van desde la advertencia hasta la hospitalización en establecimientos educativos. (BRASIL, 1990).

En la Ley de faltas penales, los artículos 51 a 58 se refieren a loterías no autorizadas, específicamente en relación con la hipótesis del "jogo do bicho", tradicional quiniela ilegal de Brasil. El párrafo 2 del artículo 51 define una lotería como cualquier operación que, a través de la distribución de boletos, listas, cupones, vales, letreros, símbolos o medios similares, hace que el sorteo de premios u otros bienes dependa de la lotería. Su promoción y su extracción se caracterizan por la declaración normativa del artículo 51, que incurre en lo que vende o expone a la venta, tiene bajo su custodia con el fin de vender, introducir o intentar introducir en circulación billetes de lotería no autorizados. Téngase en cuenta que la lotería vuelve a la ganancia de bien o dinero basada exclusivamente en el factor suerte, criminalizó su explotación sin autorización legal, como se destaca en el $\S 3$ del artículo.

En este sentido, el Artículo 52 cuida de la circulación de boletos de lotería, quiniela o tómbola extranjeros; Artículo 53 de un boleto de lotería estatal en un territorio donde no puede circular legalmente; El artículo 54 de la lista de sorteo de lotería extranjera muestra o guarda; El artículo 55, de la imprenta o cualquier boleto de lotería, lista de sorteos, aviso o servicio de carteles, en un lugar donde no puede circular legalmente, y 56, de su distribución en el mismo territorio ilegal; y, finalmente, el Artículo 57 trata de la divulgación por parte de los medios, aunque de manera encubierta, de publicidad, advertencia o el resultado de la extracción de la lotería, donde la circulación de sus boletos no sería permitida. El artículo 58 trata de la explotación o realización de la lotería llamada apuestas, o la práctica de cualquier acto relacionado con su realización o explotación.

Dicho esto, debemos preguntar, después de todo, cuál es la protección penal que se le da al trabajador inmigrante que se encuentra en las casas de juego clandestinas. Como se ha discutido en líneas anteriores, no existe un tratamiento de la ley penal específica con respecto al empleado que se encuentra en la actividad en las casas de juego. Sin embargo, es necesario 
observar que el trabajador incurre en la explotación de la actividad económica como agente, observando los ingresos obtenidos de ella. En otras palabras, además de quien establece la casa de juego y la financia, la persona que trabaja en ella, incluso en actividades de mantenimiento, aprovecha su explotación, de modo que, según la letra objetiva de la ley, su conducta puede ser considerada típica, es decir, pasible de pena. El inmigrante que se utiliza como fuerza laboral en casas de juego, en este sentido, es criminalizado en términos de dogmática legal penal. De ahí, vale la pena mencionar la hipótesis de la clasificación del empleador en los artículos 149 y 149-A del Código Penal (BRASIL, 1940), que se refieren a la reducción del trabajador (inmigrante o nacional) a la condición análoga a la de esclavo y trata de personas, respectivamente, cuando, por otro lado, el trabajo inmigrante es víctima del sistema legal. En términos generales, la ley otorga al inmigrante un doble trato con respecto a su uso como fuerza laboral en el contexto de una actividad económica criminalizada: a veces se trata como una víctima, al observar las condiciones típicas de la conducta de los artículos 149 y 149-del código penal; otras veces, como agente, cuando dichos aspectos no se verifican, a pesar de la relación de vulnerabilidad con el que establece y explota efectivamente la actividad económica en cuestión.

\section{CONCLUSIÓN}

El derecho penal brasileño no tiene en cuenta, en términos de atribución de responsabilidad, las condiciones de vulnerabilidad de los agentes en la conducta tipificada. Con la excepción de la prostitución, que en el país no es un delito per se, pero cuya explotación está tipificada por el artículo 229, con respecto al narcotráfico y, más específicamente, a las casas de apuestas ilegales, inmigrantes que, en busca de mejores condiciones de vida, llegan a Brasil, atraídos por la facilidad de trabajar en mercados ilícitos, se penalizan cuando no se verifican las condiciones que los rodean como víctimas de trata de personas, de conformidad con el artículo 149-A del Código Penal, o cuando se reducen a condiciones análogo al de los esclavos, artículo 149 de la ley penal. Los intensos flujos migratorios en América Latina, que llevan a los inmigrantes a Brasil, dadas las deficiencias 
sociales estructurales, a veces se vuelcan hacia mercados ilícitos, generando riesgos añadidos a estas personas ante un sistema legal no receptivo, que rechaza hacer distinciones entre las distintas situaciones criminógenas de cada individuo.

\section{BIBLIOGRAFÍA}

ARÉVALO, Jorge et al. Migración intercensal de seis países de América Latina. Naciones Unidas Comisión Económica para América Latina y el Caribe (CEPAL), 1974.

AZOSE, Jonathan J.; RAFTERY, Adrian E. Estimation of emigration, return migration, and transit migration between all pairs of countries. Proceedings of the National Academy of Sciences, v. 116, n. 1, p. 116-122, 2019.

BAENINGER, Rosana. Fases e faces da migração em São Paulo. Campinas: Nepo/Unicamp, 2012.

BAENINGER, Rosana; MESQUITA, Romeu Bonk. Integração regional e fronteiras: desafios para a governança das migrações internacionais na América Latina. Revista Transporte y Territorio, n. 15, p. 146-163, 2016.

BALÁN, J. Migraciones e desarrollo capitalista en el Brasil: ensaio de interpretación histórico-comparativa. Migración y Desarrollo, CLACSO, 1974.

BASSO, Pietro. L'ascesa del razzismo nella crisi globale. Razzismo di stato. Stati Uniti, Europa, Italia. Milano: Franco Angeli, p. 5-46, 2010.

BEINE, Michel; BOURGEON, Pauline; BRICONGNE, Jean-Charles. Aggregate fluctuations and international migration. The Scandinavian Journal of Economics, v. 121, n. 1, p. 117-152, 2019.

BRASIL. CONSTITUIÇÃO DA REPÚBLICA FEDERATIVA DO BRASIL DE 1988. Brasília, 5 de outubro de 1988. Disponível em: $<$ http://www.planalto.gov.br/ccivil_03/constituicao/constituicao.htm>. Acesso em 5 de julho de 2019. 
BRASIL. DECRETO-LEI No 2.848, DE 7 DE DEZEMBRO DE 1940. Código Penal. Rio de Janeiro, 7 de dezembro de 1940. Disponível em: $<$ http://www.planalto.gov.br/ccivil_03/decreto-lei/del2848compilado.htm>. Acesso em 5 de julho de 2019.

BRASIL. DECRETO-LEI $\mathbf{N}^{0}$ 3.688, DE 3 DE OUTUBRO DE 1941. Lei das Contravenções Penais. Rio de Janeiro, 3 de outubro de 1941. Disponível em: $<$ http://www.planalto.gov.br/ccivil_03/decreto-lei/del3688.htm>. Acesso em 5 de julho de 2019.

BRASIL. LEI No 13.155, DE 14 DE AGOSTO DE 2015. Estabelece princípios e práticas de responsabilidade fiscal e financeira e de gestão transparente e democrática para entidades desportivas profissionais de futebol; institui parcelamentos especiais para recuperação de dívidas pela União, cria a Autoridade Pública de Governança do Futebol - APFUT; dispõe sobre a gestão temerária no âmbito das entidades desportivas profissionais; cria a Loteria Exclusiva - LOTEX; altera as Leis n ${ }^{\circ}$ 9.615, de 24 de março de 1998, 8.212, de 24 de julho de 1991, 10.671, de 15 de maio de 2003, 10.891, de 9 de julho de 2004, 11.345, de 14 de setembro de 2006, e 11.438, de 29 de dezembro de 2006, e os Decretos-Leis n ${ }^{\circ} 3.688$, de 3 de outubro de 1941, e 204, de 27 de fevereiro de 1967; revoga a Medida Provisória nº 669, de 26 de fevereiro de 2015; cria programa de iniciação esportiva escolar; e dá outras providências. Brasília, 4 de agosto de 2015. Disponível em: <http://www.planalto.gov.br/ccivil_03/_Ato2015-2018/2015/Lei/L13155.htm\#art37>. Acesso em 10 de maio de 2019.

BRASIL. LEI No 8.069, DE 13 DE JULHO DE 1990. Dispõe sobre o Estatuto da Criança e do Adolescente e dá outras providências. Brasília, 13 de julho de 1990. Disponível em: <http://www.planalto.gov.br/ccivil_03/leis/18069.htm>. Acesso em 10 de maio de 2019.

CONNING, Arthur M. Estimación de la migración interna neta, clasificada por edad y por sexo, en las provincias y regiones de Chile durante los años 1930-1940, 1940-1952 y 1952-1960: con una breve introducción referente a la metodología. Centro Latinoamericano de Demografía, 1969. 
COSTA, Patricía Trindade Maranhão. Fighting forced labour: The example of Brazil. International Labour Office, Special Action Programme to Combat Forced Labour, 2009.

DONATO, KATHARINE M. et al. INTRODUCTION: Migration in the Americas: Mexico and Latin America in Comparative Context. The Annals of the American Academy of Political and Social Science, v. 630, p. 6-17, 2010.

GEDDES, Andrew et al. Introduction: the dynamics of regional migration governance. In: The Dynamics of Regional Migration Governance. Edward Elgar Publishing, 2019.

GONÇALVES, Maria Ortelinda Barros. Migrações e desenvolvimento. Universidade Aberta, 2009.

HARVEY, David. O enigma do capital. Revista Geografares, n. 10, p. 17-24, 2012.

HERRERA, Gioconda. Migraciones internacionales y democracia: nuevos desafíos para una ciudadanía inclusiva en América Latina. En Mirando al norte: algunas tendencias de la migración latinoamericana, compilado por Isabel Álvarez Echandi. San José: FLACSO, 2012.

HERRERA, Gioconda; SØRENSEN, Ninna Nyberg. Migraciones internacionales en América Latina: miradas críticas a la producción de un campo de conocimientos. Presentación del dossier. Íconos. Revista de Ciencias Sociales, n. 58, p. 11-36, 2017.

JONES, Richard C.; BROWN, Lawrence A. Cross-national tests of a third world development-migration paradigm: With particular attention to Venezuela. Socio-Economic Planning Sciences, v. 19, n. 5, 1985. p. 357-361.

KEMPFER, Marlene; MARTINS, Lara Caxico. Trabalho escravo urbano contemporâneo: o trabalho de bolivianos nas oficinas de costura em São Paulo. Revista do Direito Público, v. 8, n. 3, 2013. p. 77-102.

LAVENEX, Sandra. Regional migration governance-building block of global initiatives? Journal of Ethnic and Migration Studies, v. 45, n. 8, p. 1275-1293, 2019.

LOPES, Juarez; PATARRA Neide. Aménagement du peuplement au Brésil suivant les régions et entre zones urbaines et rurales, La population du Brésil, París, Comité para la 
Cooperación Internacional en las Investigaciones Nacionales sobre Demografía (CICRED), 1975.

MARINUCCI, Roberto; $\quad$ MILESI, Rosita. Migrações internacionais contemporâneas. Instituto Migrações e Direitos Humanos, 2005.

MARTINE, George R. Migraciones internas:¿ Investigación para qué?. Notas de población, 1979.

MARTÍNEZ PIZARRO, Jorge; CANO CHRISTINY, María Verónica; CONTRUCCI, Magdalena Soffia. Tendencias y patrones de la migración latinoamericana y caribeña hacia 2010 y desafíos para una agenda regional. Santiago de Chile: Comisión Económica para América Latina y el Caribe (CEPAL), 2014.

MASSEY, Douglas S. et al. A missing element in migration theories. Migration Letters, v. 12, n. 3, p. 279-299, 2015.

MORRISON, Andrew R. Violence or economics: what drives internal migration in Guatemala?. Economic Development and Cultural Change, v. 41, n. 4, 1993. p. 817-831.

RINCÓN, M. La investigación de las migraciones internas en los censos de población. América Latina: aspectos conceptuales de los censos del 2000, 1999.

RODRÍGUEZ, Jorge. Paradojas y contrapuntos de dinámica demográfica metropolitana: algunas respuestas basadas en la explotación intensiva de microdatos censales. Santiago de Chile: movilidad espacial y reconfiguración metropolitana, 2007. p. 19-52.

RODRÍGUEZ, Víctor Gabriel de Oliveira. Fundamentos do direito penal brasileiro: lei penal e teoria geral do crime. São Paulo: Atlas, 2010.

SASSEN, Saskia. Cities in a world economy. Sage Publications, 2018.

SAWYER, Donald R. Frontier expansion and retraction in Brazil. Univ. federal de Minas Gerais, Centro de desenvolvimento e planejamento regional, 1982.

SEELKE, Clare Ribando. Trafficking in persons in Latin America and the Caribbean. DIANE Publishing, 2010. 
VIGNOLI, Jorge Rodríguez; BUSSO, Gustavo. Migración interna y desarrollo en América Latina entre 1980 y 2005: un estudio comparativo con perspectiva regional basada en siete países. United Nations Publications, 2009.

VILLA, Miguel; RIVERA, Felipe. Una visión histórica de los esfuerzos de medición de la migración interna. Aproximación preliminar. Taller Nacional sobre Migración interna y desarrollo en Chile: diagnóstico, perspectivas y política, 2007.

VILLEN, Patricia. Polarização do mercado de trabalho e a nova imigração internacional no Brasil. SEMINÁRIO DO TRABALHO: Trabalho e políticas sociais no século, v. 21, n. 8, 2012.

Recebido em: 27/07/2019

Aprovado em: 25/11/2019

Publicado em: 26/12/2019 